Original Article

\title{
Comparison of Surgical Outcome of Anterior Circulation Aneurysms With and Without Proximal Temporary Artery Occlusion
}

\author{
Sameer Aryal ${ }^{1}$, Habib Sultan ${ }^{2}$, Muhammad Anwar Chaudary ${ }^{2}$ \\ ${ }^{1}$ Department of Neurosurgery, National Academy of Medical Sciences, Bir Hospital, Nepal \\ ${ }^{2}$ Department of Neurosurgery, AMC/PGMI, Punjab Institute of Neurosciences (PINS), Lahore General \\ Hospital, Lahore - Pakistan
}

\begin{abstract}
Background: Intracranial aneurysm due to its subtle nature and adverse impact pose major challenges in the clinical care setting. Proximal temporary artery occlusion (TAO) is a routine technique used for the treatment of aneurysms often to avoid premature rupture of aneurysms and to facilitate final dissection. However, its routine use and overall safety are often questioned. The focus of this study was to compare the outcome of the TAO vs. no TAO during aneurysm surgery in terms of clinically significant postoperative ischemic changes due to vasospasm.
\end{abstract}

Material and Methods: A quasi-experimental study was conducted at Lahore General Hospital wherein 82 patients were enrolled. This study was conducted when the first author was working as PGR at LGH Lahore during 2015 to 2017. Patients were followed from admission to three-month post-op. During the follow-up, patients with clinical substantial post-op ischemic changes were calculated on CT Angiography for the presence of vasospasm.

Results: Mean age of the patients was 45.23 years. Proximal TAO was done in $30 \%(n=25)$ patients. Clinically significant post-op ischemic changes were seen in $29.3 \%(n=24)$ patients. Of the patients who underwent proximal TAO, longer occlusion time (> 10 mins) was significantly associated with ischemic changes ( $p$-value 0.015 ). Age $>50$ years also showed a statistically significant association with clinical vasospasm ( $p$-value $<0.001)$.

Conclusion: Temporary proximal artery clipping when employed within a limited duration appears to be safe and has no significant impact on clinical vasospasm. Since vasospasm is multifactorial, avoiding a longer duration of proximal TAO in patients with advancing age could decrease the frequency of post-operative ischemic changes due to vasospasm in such patients.

Keywords: Vasospasm, Intracranial, Aneurysm, Temporary Clipping, Ischemic Changes, Subarachnoid Hemorrhages (SAH).

Corresponding Author: Sameer Aryal

Department of Neurosurgery, AMC/PGMI

Punjab Institute of Neurosciences (PINS)
Lahore General Hospital, Lahore Pakistan

Email: dr.sameeraryal@gmail.com 
Date of Submission: 10-06-2021

Date of Revision: 09-08-2021

Date of Acceptance: 15-09-2021

Date of Online Publishing: 30-12-2021

Date of Print: 31-12-2021

DOI: $10.36552 /$ pjns.v25i4.615

\section{INTRODUCTION}

The intracranial aneurysm has a relative prevalence of $3-6 \%$ across the global population with predominance amongst the females is associated with impairment in the wall of cerebral vessels leading to localized swelling or out pouching of the vessel. $^{1}$ An aneurysm was discovered in 1933 through cerebral angiography by Egas Moinz. ${ }^{2}$ Whereas, the planned intracranial surgery for saccular aneurysm was performed by Dott in the same year. ${ }^{3}$ Silent Ischemic events have a prevalence rate of $10-69 \%$ during diagnostic and interventional endovascular procedures and could also be found in multiple of 10 - 30\% of cases. ${ }^{4}$ Although aneurysms are comparatively small, the condition is associated with considerable mortality and morbidity. The commonly reported implication is the subarachnoid hemorrhage which is secondary to rupture. The primary focus of the treatment approach is preventing re-rupture. ${ }^{5}$

Regarding various treatments, the microsurgical clipping has a superior outcome compared to the natural history of un-ruptured intracranial aneurysms amongst the patient with an estimated life expectancy of 10 years or more. Studies exploring surgery as the treatment option reports more than $7.5 \%$ bleeding associated morbidity and mortality in 10 years versus $3.4 \%$ permanent morbidity and $0.8 \%$ rate of mortality associated with surgery. ${ }^{5}$ In this context, proximal TAO is a crucial technique for dissection of an aneurysm and clipping the neck leading to the bleeding control associated with premature rupture during the surgical procedure..$^{7-11}$

Following a study involving $50 \%$ cases encompassing the application of proximal TAO during surgery, around 34\% developed vasospasm postoperatively (versus 20\% without proximal TAO, $p<0.006$ ). The total duration of the proximal TAO was also reported to be associated with the development of vasospasm defined by Transcranial Doppler (TCD). Further, the higher number of patients also developed MCA aneurysm following the temporary clipping $48 \%$ versus $22 \%$ ( $p<0.0001) .{ }^{12}$ Accordingly, it could be argued that the probability of vasospasm is aggravated by the application of proximal TAO during microsurgical clipping with mean occlusion time with TAO being reported as $9.7 \pm 14.3$ mins. $^{4}$

With regards to this, the focuses of the study encompass the comparison of the outcome of proximal TAO against no TAO in patient undergoing surgery for intracranial aneurysms. Regarding this, controversial results have been reported within the research evidence resulting in a dispute relating to the benefits or harm associated with proximal TAO. Hence this study focuses on investigating whether the postoperative ischemic changes attributed to vasospasm have been associated with proximal TAO or not.

\section{MATERIALS AND METHODS}

\section{Study Design and Setting}

The research adopted a quasi-experimental study which was conducted at Lahore General Hospital.

\section{Inclusion Criteria}

For the experiment, a sample size of 82 cases were calculated with $80 \%$ power of test at $5 \%$ level of significance and considering for the expected percentage of MCA Aneurysm i.e., 48\% with proximal TAO and $22 \%$ without proximal TAO for management of patients with intracranial aneurysms. The population sample was recruited using consecutive sampling techniques with the 
eligibility criteria of age between 20 - 70 years diagnosed with intracranial aneurysms following operational definition.

\section{Exclusion Criteria}

Individuals with redo surgery (on medical records); prior history of neurological and psychiatric illness; hypertensive (BP $\geq 140 / 90$ $\mathrm{mmHg}$ ) or diabetics (BSR > $186 \mathrm{mg} / \mathrm{dl}$ ) were excluded from the study.

\section{Data Collection}

A total of 82 patients fulfilling the eligibility criteria were enrolled from the wards of the Department of Neurosurgery, Lahore General Hospital, Lahore. Pre-design proforma was used for data collection. Informed consent of the participant was obtained with an appropriate record for the demographic variables of the participants. Information such as the intraoperative rupture of an aneurysm, placement of proximal TAO, and duration of TAO has been noted with the cases categorized into two groups: Group A with proximal TAO and B without proximal TAO.

\section{Clinical Management and Followup}

The procedure was conducted at the Department of Neurosurgery, Lahore General Hospital under general Anesthesia with the prior evaluation of the patient and follow-up after surgery for evaluating any new neurological deficits. Participants were transferred to the postoperative ward and followed-up for $3-5$ days with the evaluation for the development of neurological deficit, confusion, the decline in GCS of at least 2 points, and/or cerebral infarction in the territory vessels related and unrelated to the clipped aneurysm. CT scans were performed within 72 hours post-op on all cases for detection of post-op complications and vasospasm. The participant was followed-up in OPD for 3 months wherein, they were evaluated on CTA for the presence of intracranial aneurysm and vasospasm using predesigned proforma for collection of information.

\section{Data Analysis}

The collected data was analyzed using SPSS Version 25 with a quantitative variable such as age, duration of SAH (Subarachnoid Hemorrhages), and duration of temporary clipping presented as mean and standard deviation. Qualitative variables like gender, WFNS Grade, Fisher Grade, location of the aneurysm, intraoperative rupture, and clinical vasospasm were presented as frequency and percentage. Chi-square test or Fisher's exact test were conducted whenever applicable for comparison of the outcomes. A P-value of less than 0.05 was taken as significant. Significance of vasospasm and presence of MCA aneurysm whenever present with the confounding variables like age, gender, duration of SAH, WFNS (World Federation of Neurological Surgeons) grade, Fisher grade, location of aneurysm, intraoperative rupture, and duration of proximal TAO were cross evaluated with the outcome using multivariate analysis.

\section{RESULTS}

\section{Age and Gender of Patients}

The mean age of patients/participants was 45.23 \pm 12.064 years with the majority of the patient being females (65.9\%) versus males (34.1\%). Around $28 \%$ of the participant presented preoperative Focal Neurological Deficit (FND).

\begin{tabular}{|lcc|}
\hline Table 1: WFNS Grade Distribution. \\
Grade I & Frequency & Percent \\
Grade II & 40 & 48.8 \\
Grade III & 18 & 22 \\
Grade IV & 19 & 23.2 \\
Total & 5 & 6.1 \\
\hline
\end{tabular}


Further, the mean duration of SAH till surgery was $18.09 \pm 5.195$ days with minimum days of 9 and maximum days of 37 .

Statistical significance was reported between the duration of the TAO for both groups $A$ and $B$

Table 2: Fisher Grade Distribution.

\begin{tabular}{lcc} 
Fisher Grade & Frequency & Percentage \\
Grade I & 9 & 11 \\
Grade II & 21 & 25.6 \\
Grade III & 33 & 40.2 \\
Grade IV & 19 & 23.2 \\
Total & $\mathbf{8 2}$ & $\mathbf{1 0 0}$ \\
\hline
\end{tabular}

Table 3: Aneurysm Location.

$\begin{array}{lcc}\text { ACOM Aneurysm } & 39 & 47.6 \% \\ \text { MCA Aneurysm } & 34 & 41.5 \% \\ \text { PCOM Aneurysm } & 6 & 7.3 \% \\ \text { ICA Bifurcation Aneurysm } & 3 & 3.7 \% \\ \text { Total } & \mathbf{8 2} & \mathbf{1 0 0 \%}\end{array}$

(p-value < 0.001). Similarly, post-op ischemic changes were reported for $29.3 \%$ of participants with 10 from Group A and 14 from Group B however, no association between outcome and treatment group was observed, $\mathrm{p}$-value $=0.191$ (Table-5).

Table 4: Study Group.

\begin{tabular}{lcc} 
& Frequency & Percentage \\
Group A & 25 & 30.5 \\
Group B & 57 & 69.5 \\
Total & 82 & 100 \\
\hline
\end{tabular}

Table 5: Comparison of ischemic changes according to treatment group.

\begin{tabular}{|c|c|c|c|}
\hline Study & \multicolumn{2}{|c|}{ Ischemic Changes } & p-value \\
\hline Group & Yes & No & \\
\hline Group A & 10 (40.0\%) & 15 (60.0\%) & 0191 \\
\hline Group B & 14 (24.6\%) & 43 (75.4\%) & \\
\hline Total & 24 (29.3\%) & 58 (70.7\%) & \\
\hline
\end{tabular}

Table 6: Comparison of age group and ischemic changes according to groups.

\begin{tabular}{|c|c|c|c|c|c|}
\hline \multicolumn{2}{|c|}{ Study Group } & \multicolumn{2}{|c|}{ Ischemic Changes } & \multirow{2}{*}{ Total } & \multirow{2}{*}{ p-value } \\
\hline & Age Value & Yes & No & & \\
\hline \multirow{3}{*}{ Group A } & $\leq 50$ & $3(18.8 \%)$ & 13 (81.3\%) & 16 & \multirow{3}{*}{$0.009^{*}$} \\
\hline & $>50$ & 7 (77.8\%) & 2 (22.2\%) & 9 & \\
\hline & Total & 10 (40.0\%) & 15 (60.0\%) & 25 & \\
\hline \multirow{3}{*}{ Group B } & $\leq 50$ & 7 (17.1\%) & 34 (82.9\%) & 41 & \multirow{3}{*}{$0.047^{*}$} \\
\hline & $>50$ & 7 (43.8\%) & 9 (56.3\%) & 16 & \\
\hline & Total & 14 (24.6\%) & 43 (75.4\%) & 57 & \\
\hline \multirow{3}{*}{ Total } & $\leq 50$ & 10 (17.5\%) & 47 (82.5\%) & 57 & \multirow{3}{*}{$0.001^{*}$} \\
\hline & $>50$ & 14 (56.0\%) & 11 (44.0\%) & 25 & \\
\hline & Total & 24 (29.3\%) & 58 (70.7\%) & 82 & \\
\hline
\end{tabular}

${ }^{*} p$-value is significant at 0.05

Table 7: Comparison of proximal TAO and ischemic changes controlling the effect of age.

\begin{tabular}{|c|c|c|c|c|c|}
\hline \multirow{2}{*}{ Age Group (In Years) } & & \multicolumn{2}{|c|}{ Ischemic changes } & \multirow{2}{*}{ Total } & \multirow{2}{*}{ p-value } \\
\hline & Duration of TAO & Yes & No & & \\
\hline \multirow[t]{3}{*}{50} & Less than 10 & 7 (13.2\%) & 46 (86.8\%) & 53 & \\
\hline & More than 10 & $3(75.0 \%)$ & 1 (25.0\%) & 4 & $0.015^{*}$ \\
\hline & Total & 10 (17.5\%) & 47 (82.5\%) & 57 & \\
\hline \multirow[t]{3}{*}{$>50$} & Less than 10 & 11 (50.0\%) & 11 (50.0\%) & 22 & \\
\hline & More than 10 & 3 (100.0\%) & 0 (0.0\%) & 3 & 0.230 \\
\hline & Total & 14 (56.0\%) & $11(44.0 \%)$ & 25 & \\
\hline
\end{tabular}

${ }^{*} p$-value significant at 0.05 


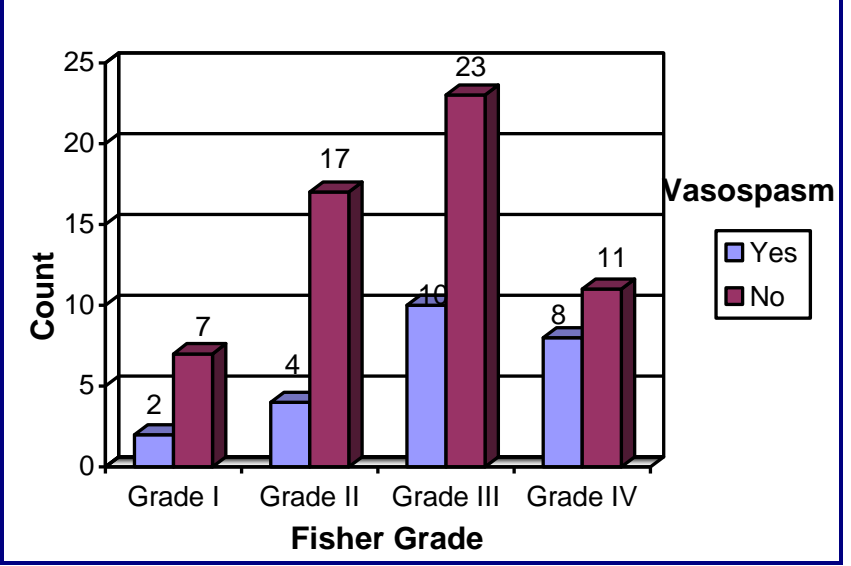

Figure 1: Frequency of Clinical Vasospasm with Fisher Grade.

Clinical vasospasm increases with the increase in grade but the association between fishers' grade and vasospasm was not significant ( $p$-value 0.211).

\section{DISCUSSION}

Intracranial aneurysms are potentially lifethreatening and disabling vascular conditions with formidable challenges in the treatment. The bleeding of aneurysm is associated with a substantial increment in the risk of rebleeding in the first 24 hours up to $4.1 \%$ on the first day and $1.5 \%$ for each subsequent day with a rebleed rate of $19 \%$ on the first two weeks cumulatively. ${ }^{13-14}$ The primary goal of the treatment procedure is to eliminate the chance of rebleeding. Regarding vasospasm, it is related to clinically significant events such as acute stroke, Delayed Ischemic Neurological deficits (DIND), Delayed Ischemic Changes (DIC), and new-onset altered sensorium. It is a commonly reported incident following the rupture of aneurysms with the onset being reported after $3-5$ days of the rupture and lasting up to 14 - 21 days. Vasospasm despite clipping or coiling of ruptured aneurysms is a leading cause of poor health outcomes. Existing treatment has been reported to be unsuccessful in the elimination or treatment of cerebral vasospasm due to the multifactorial and complicated nature of the condition. ${ }^{15}$

Advanced age, male sex, and higher fisher grades predicted postoperative ischemic changes whereas the timing of surgery did not. ${ }^{16}$ In our study frequency of ischemic changes were seen in 24 (29.3\%) patients with intracranial aneurysm undergoing microsurgical clipping in either group. It was overall associated with elderly age i.e., > 50 years of age patients ( $p$-value 0.001 ). In both, group $A$ and group $B$, ischemic changes were found associated with patients aged more than 50 years ( $p$-value $0.009 \& 0.047$ respectively) In our study, the frequency of clinical vasospasm increases with the increase in fisher grade, but the association was not statistically significant ( $p$-value 0.211 ). In our study frequency of clinical vasospasm was lower than that reported in the above-mentioned study and there was no difference between either group. Plus, we didn't encounter any unruptured MCA aneurysms during our follow-up period of 3 months. Hence, our results contradict this study. Furthermore, finding from the study also elucidates no correlation between clinical vasospasm and gender.

\section{CONCLUSION}

Proximal Temporary Artery Occlusion when introduced within a limited duration appears to be safe with no substantial associated/impact on vasospasm. Since, vasospasm is multifactorial, avoiding a longer duration of proximal TAO in patients with advancing age could lower the frequency of post-operative ischemic changes associated with vasospasm.

\section{REFERENCES}

1. Hamid RS, Tanveer-ul-Haq, Chishti I, Azeemuddin M, Sajjad Z, Salam B. Treatment of intracranial aneurysms using detachable coils; initial results at a university hospital in Pakistan. J Pak Med Assoc. 2010; 60 (8): 638-41. 
2. Artico $M$, Spoletini $M$, Fumagalli $L$, Biagioni $F$, Ryskalin L, Fornai $F$, et al. Egas Moniz: 90 Years (1927 - 2017) from Cerebral Angiography. Front Neuroanat. 2017 Sep. 19: 11.

3. Dott NM. Intracranial Aneurysms: Cerebral ArterioRadiography: Surgical Treatment. Edinb Med J. 1933; 40 (12): T219-40.

4. Krayenbühl $N$, Erdem $E$, Oinas $M$, Krisht AF. Symptomatic and Silent Ischemia Associated with Microsurgical Clipping of Intracranial Aneurysms. Stroke, 2009; 40 (1): 129-33.

5. Johnson $M$, Christensen $C C$, Kagermann $H$. Reinventing Your Business Model. Harv Bus Rev. 2008; 87: 52-60.

6. Krisht AF, Gomez J, Partington S. Outcome of Surgical Clipping of Unruptured Aneurysms as it Compares with a 10-Year Nonclipping Survival Period. Neurosurgery, 2006; 58 (2): 207-16.

7. Akyüz G, Doğan $O$, Şar V, Yargiç Lí, Tutkun H. Frequency of dissociative identity disorder in the general population in Turkey. Compr Psychiatry, 1999; 40 (2): 151-9.

8. Charbel FT, Ausman JI, Diaz FG, Malik GM, Dujovny M, Sanders J. Temporary clipping in aneurysm surgery: Technique and results. Surg Neurol. 1991; 36 (2): 83-90.

9. Doyle CJ, Post H, Burney RE, Maino J, Keefe M, Rhee KJ. Family participation during resuscitation:
An option. Ann Emerg Med. 1987; 16 (6): 673-5.

10. Kang H-L, Benzer S, Min K-T. Life extension in Drosophila by feeding a drug. Proc Natl Acad Sci. 2002; 99 (2): 838-43.

11. Kang SHK, McDermott KB, Roediger HL. Test format and corrective feedback modify the effect of testing on long-term retention. Eur J Cogn Psychol. 2007; 19 (4-5): 528-58.

12. Woertgen $C$, Rothoerl RD, Albert R, Schebesch K$\mathrm{M}$, Ullrich O-W. Effects of temporary clipping during aneurysm surgery. Neurol Res. 2008; 30 (5): 542-6.

13. Petridis AK, Kamp MA, Cornelius JF, Beez T, Beseoglu K, Turowski B, et al. Aneurysmal Subarachnoid Hemorrhage. Dtsch Aerzteblatt. 2017; 13: 114.

14. Tang C, Zhang T-S, Zhou L-F. Risk Factors for Rebleeding of Aneurysmal Subarachnoid Hemorrhage: A Meta-Analysis. Ai J, editor. PLoS One, 2014; 9 (6): e99536.

15. Inagawa T. Risk Factors for Cerebral Vasospasm Following Aneurysmal Subarachnoid Hemorrhage: A Review of the Literature. World Neurosurg. 2016; 85: $56-76$.

16. Yao X, Tangri N, Gersh BJ, Sangaralingham LR, Shah ND, Nath KA, et al. Renal Outcomes in Anticoagulated Patients With Atrial Fibrillation. J Am Coll Cardiol. 2017; 70 (21): 2621-32.

\section{Additional Information}

Disclosures: Authors report no conflict of interest.

Ethical Review Board Approval: The study was conformed to the ethical review board requirements.

Human Subjects: Consent was obtained by all patients/participants in this study.

\section{Conflicts of Interest:}

In compliance with the ICMJE uniform disclosure form, all authors declare the following:

Financial Relationships: All authors have declared that they have no financial relationships at present or within the previous three years with any organizations that might have an interest in the submitted work.

Other Relationships: All authors have declared that there are no other relationships or activities that could appear to have influenced the submitted work.

\section{AUTHORS CONTRIBUTIONS}

\begin{tabular}{|l|l|l|}
\hline Sr.\# & Author's Full Name & Intellectual Contribution to Paper in Terms of: \\
\hline 1. & Sameer Aryal & $\begin{array}{l}\text { 1. Study design and methodology, Paper writing, referencing, and data } \\
\text { calculations. }\end{array}$ \\
\hline 2. & Habib Sultan & 2. Analysis of data, interpretation of results and literature review. \\
\hline 3. & M Anwar Chaudhary & 3. Analysis of data and quality insurer. \\
\hline
\end{tabular}

